F. Osmond; a plea for uniform international specifications for iron and steel, by Mr. Ast and Mr. Barba; and an account of the advantages to be derived from the formation of an international laboratory for investigating the methods of analysing iron and steel, by Dr. H. Wedding. In the last-mentioned paper it was pointed out that the relations of buyers and sellers in the iron and steel trades would be put on a much safer basis if standard methods were worked out so that any chemist of ordinary skill could be trusted to carry them out. This could best be done at a central laboratory, where the work done in various countries could be collated and reduced to a common standard. A competent director for such a laboratory had been found in Baron Jüptner, and ample accommodation had been granted at Zürich by the Swiss Government. Subscriptions towards the cost of maintenance for ten years had been promised by some of the large British and continental ironworks, and it was consequently decided to begin operations in January next.

In addition to the discussions bearing upon the testing of iron and steel, several important memoirs were discussed in the Section, dealing with artificial building materials, the principal ones being on the relation between the chemical composition of natural building stones and their resistance to weathering, by $\mathrm{Mr}$. A. Buess (Hamburg); on the testing of earthenware pipes, by Mr. Gary (Berlin); on the hardening process of calcareous cements, by Mr. D. W. Michaelis (Berlin); and on the determination of the quality of hydraulic cements, by Mr. M. Meyer (Malstatt).

The governing body, consisting of Prof. Tetmajer, Prof. Martens (Berlin), Prof. Debray (Paris), Mr. Berger (Vienna), and Prof. Belelubsky (St. Petersburg), was reelected; and, in view of the fact that the whole of the Council of the Iron and Steel Institute had joined the Association, it was decided to have representatives of the English-speaking countries on the governing body, Mr. R. A. Hadfield (Sheffield) and Captain Carter (U.S. Army) being those chosen. It was further decided that in future the proceedings of the Congress will be published in English, as well as in French and German.

\section{THE RADIATION OF LIGHT IN THE MAGNETIC FIELD.}

$\mathrm{D}^{\mathrm{u}}$

URING the past few months some interesting experiments have been made regarding the partial polarisation of radiations emitted by certain luminous sources when they are placed under the influence of a magnetic field. Important investigations in this direction have been made by Dr. Zeeman, of the University of Leyden, who has shown that the perturbations experienced by the ions, under the influence of magnetic forces, produced new periods of luminous vibrations. Continuing this work, Messrs. Egoroff and Georgiewsky (Comptes rendus, April 5, 1897), with the aid of a Rowland grating and a Ruhmkorff coil, have observed a feeble broadening of the lines $D_{1}$ and $D_{2}$ in the spectra of both axial and equatorial radiations. In investigating the appearance of coloured flames of polarised rays by using the Savart analyser, it was observed that the partial rectilinear polarisation of rays directed towards the equator of the magnetic field was easily observed, not only in flames of sodium, lithium and potassium, but in induction sparks between magnesium electrodes. In the cases of carbon, aluminium, mercury, zinc, bismuth and iron, the Savart analyser showed no indication of rectilinear polarisation. In a second communication to the same journal (Comptes rendus for May 3), the results there enumerated may be summed up as follows. The relative quantity of equatorial radiations emitted by a sodium flame, and polarised rectilinearly, varies with the intensity of the magnetic field according to a particular curve. Under the influence of a magnetic field of given intensity, the quantity of the light polarised rectilinearly, and emitted equatorially by the sodium flame, varies with the temperature of the flame. In studying the change of spectra of metals in a field of considerable intensity, a modification of the method of procedure was adopted, and resulted in the discovery of the rectilinear polarisation of the equatorial radiations. Nearly all the metals employed-namely, $\mathrm{Cu}, \mathrm{Tl}, \mathrm{Zn}$, $\mathrm{Cd}$, In, $\mathrm{Mg}, \mathrm{Ca}, \mathrm{Ba}, \& \mathrm{c}$ - - showed polarisation exclusively for those rays that are easily reversed. The phenomenon, the authors state, "is observed in a very instructive manner for the copper in the green part of the spectrum (the change is very large for the ray 5105 , most feeble for 5153, and zero for the long waves 5217 to 5292). For indium, the change only occurred for the violet ray at 4510 , while the others $(6193,5230,5900$, 4680,4616 and $\left.463^{8}\right)$ were not influenced by the field at all." In experiments with Geissler tubes containing hydrogen and helium, no definite results up to the present have been obtained.

In the experiments just referred to, it may be mentioned that all the observations were made with the eye. It would, however, be interesting to inquire whether the photographic plate would register these small variations, for then we should have a permanent record of a phenomenon which is not so very easy to observe, or which, at any rate, might be subject to "personal" error. The application of photography to show such effects has been accomplished by Mr. Alexander Anderson, assisted by Mr. Adeney. They employed a Rowland grating of $2 \mathrm{I} \cdot 5$ feet radius, and obtained photographs of the cadmium spectrum, the source of light being a spark between cadmium electrodes from the secondary of a large induction coil. Mr. Anderson's account of his experiments is briefly summarised as follows.

"Three lines are very distinct in all the photographs, namely, those of wave-lengths 5086, 4800 , and 4678 tenthmetres. Photographs were taken, both without and with a magnetic field, the time of exposure being exactly the same in both cases. This field was produced by a large electro-magnet excited directly by a dynamo giving a pressure with open circuit of 70 volts, the flat poles of the electro-magnet being covered with ebonite, so that they could be brought very close to the cadmium electrodes without interfering with the sparking. The field thus produced was practically uniform, and its intensity was found to be about I7,000 C.G.S. units."

In the first photographs the slit width was about $\mathrm{OOI}$ $\mathrm{cm}$., but in the later photographs about twice this width was used. An examination of the photographs showed that there was no evidence of any effect of the magnetic field, though the definition of the lines was all that could be desired, namely, very clear and sharply defined. When it be remembered "that a length of one centimetre in the photograph corresponds to a change of wave-length of 26 tenth-metres, and since an increase of breadth of a line of one-tenth of a millimetre (and probably much less than this) could easily be seen on the photographs, there could not have been a change in the period of oscillation of as much as one part in 20,000 ."

To account for this negative result, Mr. Anderson suggests two possible reasons: viz. that perhaps the magnetic field was not of sufficient intensity, or that the exposure (thirty minutes for the narrow slit) was not long enough. He states, however, that with an eyepiece in place of the camera, he "saw (or fancied he saw) a widening of the lines."

The whole phenomenon of the widening of the lines in the spectra of metallic substances in a magnetic field is, however, of great interest to both physicists and astro-physicists, and it is important that both eye and photographic results should be obtained when possible.

No. 1453 , voL. 56] 